\title{
Gene flow relates to evolutionary divergence among populations at the range margin
}

\author{
Peter Kaňuch $^{1}$, Berrit Kiehl ${ }^{2,3}$, Anna Cassel-Lundhagen ${ }^{3}$, Ane T Laugen ${ }^{3,4,5}$, Matthew Low ${ }^{3}$, Åsa Berggren $^{\text {Corresp. } 3}$ \\ 1 Institute of Forest Ecology, Slovak Academy of Sciences, Zvolen, Slovakia \\ 2 Department of Ecology and Genetics, Uppsala University, Uppsala, Sweden \\ 3 Department of Ecology, Swedish University of Agricultural Sciences, Uppsala, Sweden \\ 4 Bioeconomy Research Team, Novia University of Applied Sciences, Ekenäs, Finland \\ 5 Department of Natural Sciences, University of Agder, Kristiansand, Norway \\ Corresponding Author: Åsa Berggren \\ Email address: asa.berggren@slu.se
}

Background. Morphological differentiation between populations resulting from local adaptations to environmental conditions is likely to be more pronounced in populations with increasing genetic isolation. In a previous study a positive clinal variation in body size was observed in isolated Roesel's bush-cricket, Metrioptera roeselii, populations, but were absent from populations within a continuous distribution at the same latitudinal range. This observational study inferred that there was a phenotypic effect of gene flow on climateinduced selection in this species. Methods. To disentangle genetic versus environmental drivers of population differences in morphology, we measured the size of four different body traits in wild-caught individuals from the two most distinct latitudinally-matched pairs of populations occurring at about $60^{\circ} \mathrm{N}$ latitude in northern Europe, characterised by either restricted or continuous gene flow, and corresponding individuals raised under laboratory conditions. Results. Individuals that originated from the genetically isolated populations were always bigger (femur, pronotum and genital appendages) when compared to individuals from latitudinally-matched areas characterised by continuous gene flow between populations. The magnitude of this effect was similar for wild-caught and laboratory-reared individuals. We found that previously observed size cline variation in both male and female crickets was likely to be the result of local genetic adaptation rather than phenotypic plasticity. Conclusions. This strongly suggests that restricted gene flow is of major importance for frequencies of alleles that participate in climate-induced selection acting to favour larger phenotypes in isolated populations towards colder latitudes. 


\section{Gene flow relates to evolutionary divergence among populations at the range}

2 margin

3

4 Peter Kaňuch ${ }^{1}$, Berrit Kieh2 ${ }^{2,3}$, Anna Cassel-Lundhagen ${ }^{2}$, Ane T. Laugen ${ }^{2,4,5}$, Matthew Low ${ }^{2}$, Åsa

5 Berggren $^{2}$

6

$7 \quad{ }^{1}$ Institute of Forest Ecology, Slovak Academy of Sciences, Zvolen, Slovakia

$8 \quad$ 2Department of Ecology, Swedish University of Agricultural Sciences, Uppsala, Sweden

$9 \quad$ BDepartment of Ecology and Genetics, Uppsala University, Uppsala, Sweden

10 Bioeconomy Research Team, Novia University of Applied Sciences, Ekenäs, Finland

$11{ }^{5}$ Department of Natural Sciences, University of Agder, Kristiansand, Norway

13 Corresponding Author:

14 Åsa Berggren

15 Department of Ecology, Swedish University of Agricultural Sciences, Box 7044, 75007

16 Uppsala, Sweden

17 Email address: asa.berggren@slu.se

\section{Abstract}

Background. Morphological differentiation between populations resulting from local adaptations to environmental conditions is likely to be more pronounced in populations with increasing genetic isolation. In a previous study a positive clinal variation in body size was observed in isolated Roesel's bush-cricket, Metrioptera roeselii, populations, but were absent from populations within a continuous distribution at the same latitudinal range. This observational study inferred that there was a phenotypic effect of gene flow on climate-induced 26 selection in this species.

27 Methods. To disentangle genetic versus environmental drivers of population differences in 28 morphology, we measured the size of four different body traits in wild-caught individuals from the two most distinct latitudinally-matched pairs of populations occurring at about $60^{\circ} \mathrm{N}$ latitude in northern Europe, characterised by either restricted or continuous gene flow, and corresponding

31 individuals raised under laboratory conditions. 
32 Results. Individuals that originated from the genetically isolated populations were always bigger

33 (femur, pronotum and genital appendages) when compared to individuals from latitudinally-

34 matched areas characterised by continuous gene flow between populations. The magnitude of

35 this effect was similar for wild-caught and laboratory-reared individuals. We found that

36 previously observed size cline variation in both male and female crickets was likely to be the

37 result of local genetic adaptation rather than phenotypic plasticity.

38 Conclusions. This strongly suggests that restricted gene flow is of major importance for

39 frequencies of alleles that participate in climate-induced selection acting to favour larger

40 phenotypes in isolated populations towards colder latitudes.

42 Subjects: Ecology, Evolution, Entomology

43 Keywords: Adaptive divergence, Body size, Climate, Genetic isolation, Orthoptera

\section{Introduction}

Geographical patterns in phenotypic variation often reflect evolutionary and ecophysiological

processes in response to different environmental conditions, such as temperature, light-dark cycles and precipitation. Intraspecific variation in body size of ectotherms is a well-documented phenomenon (Atkinson et al., 1994; Whitman, 2008; Terribile et al., 2009; Fabian et al., 2015) and this variation often manifests as positive or negative size clines (van Voorhies, 1996; Blanckenhorn \& Demont, 2004; Whitman, 2008). Body size variation may be determined by either physiological constraints (e.g. smaller body sizes due to lack of resources such as optimal heat energy or nutrients), by local selection pressures acting to favour some phenotypes (e.g. sexspecific selection on individual's size associated with reproductive success and season length) or by their mutual effect (Blanckenhorn et al., 2006; Chown \& Gaston, 2009; Kaňuch et al., 2015). While local selection pressures promote morphological differentiation among populations (Angilletta \& Dunham, 2003; Bolnick \& Nosil, 2007), gene flow between populations can lead to so-called genetic swamping when alleles from one population spread through the other population genotype (García-Ramos \& Kirkpatrick, 1997; Lenormand, 2002). New alleles or a sudden change of allelic frequencies in the population may then counteract local phenotypic 61 adaptation (Kawecki \& Ebert, 2004; Crispo, 2008; Tigano \& Friesen, 2016; Pedersen et al., 2017). In contrast, reduced level of gene flow increases genotypic differentiation between 
63 populations while phenotypic divergence is often correlated with the degree of isolation 64 (Lenormand, 2002). Therefore the relative effect of selection pressures depends on both the strength of the selection and on gene flow that is determined by the degree of isolation between 66 populations (Hendry et al., 2002; Raeymaekers et al., 2014; Berner \& Thibert-Plante, 2015). If gene flow among populations or sub-populations differs throughout a species' range of distribution, this gene flow will contribute to a varying degree to the phenotypic differentiation that is primarily driven by environmental factors (García-Ramos \& Kirkpatrick, 1997).

Roesel's bush-cricket, Metrioptera roeselii (Orthoptera: Tettigoniidae), is widespread and continuously distributed across continental Europe (Harz, 1957; de Jong \& Kindvall, 1991; Maas et al., 2002) and has recently expanded its range northwards via several human-mediated longdistance colonization events, which have been revealed by genetic traces (Kaňuch et al., 2013; Preuss et al., 2014). At the northern range limit the species displays two different geographical distribution patterns. On the eastern side (the Baltic States and Finland) the distribution range extends as interconnected populations all the way to the polar circle (Karjalainen, 2009). On the western side (Denmark and the Scandinavian Peninsula) and some islands in the Baltic Sea (Åland Islands, Saaremaa), the species occurs in scattered local populations isolated from each other (Albrecht, 1963; Ahlén, 1995; Bavnhøj, 1996; Karjalainen, 2009; Kaňuch et al., 2013). The species is characterised as a habitat generalist grassland-dwelling species (Bellmann, 1985; Detzel, 1998; Ingrisch \& Köhler, 1998) where climate variation is the main source of selection pressure acting on local populations (Kenyeres \& Cservenka, 2014). Wide ranges of morphological adaptations to climate have evolved in grassland insects (Barnett \& Facey, 2016) and climate-determined season length also drives positive size clines in some Orthopteran species (reviewed by Whitman, 2008). While climate characteristics of M. roeselii populations in the two different geographical distribution patterns in northern Europe are similar across the extent of their distribution range (Cassel-Lundhagen et al. 2011; see also Fig. 1A), the genetic distances between isolated populations and their inferred founders indicate a lack of ongoing gene flow into the isolated western populations. This is in contrast to the high level of gene flow among populations within the continuous eastern distribution range and restriction of gene flow resulted in contrasting patterns in both mitochondrial and microsatellite genetic structures of these populations (Kaňuch et al., 2013). This peculiar distribution of M. roeselii and its 
94 homogenizing gene flow on phenotypic differentiation that can be associated with adaptive 95 divergence in body size as an evolutionary response to selection in a cold climate environment.

By using a set of seven latitudinally-matched population pairs in which one population

97 was geographically isolated and the other was part of the continuous distribution range, Cassel-

98 Lundhagen et al. (2011) found that the latitudinal body size variation in $M$. roeselii within the

99 two areas (continuous distribution vs. isolated populations) differed. Field collected adults from

100 isolated populations were successively larger at higher latitudes (i.e. a positive size cline), while

101 individuals from continuous populations remained similar in size in all locations for most of the

102 measured traits. Along with that, significantly higher $F_{\mathrm{ST}}$ values indicated no dispersal between

103 isolated populations in contrast to the area of continuous species distribution. This observational

104 study suggested that the size variation in the isolated populations was an adaptive response to

105 local conditions at different latitudes, while the lack of a similar latitudinal response in

106 continuous populations resulted from gene flow from surrounding areas preventing them

107 reaching the same local adaptive optima. However, the contribution of phenotypic plasticity on

108 the observed latitudinal differences in body size could not be definitively determined.

109 To investigate if the observed difference in body size between isolated and continuous-

110 range populations of $M$. roeselii could be a genetically based adaptive response to selection or

111 was simply phenotypic plasticity, we carried out a combined lab- and field-based experimental

112 study. The size of four different body traits was measured in adult individuals of both sexes that

113 originated from either laboratory or field conditions in a subset of seven previously studied

114 population pairs. We controlled for random variation in the study populations' environments

115 using individuals reared from early instars under laboratory conditions from both isolated and

116 continuous populations, and compared their differences to adult individuals collected from the

117 same populations in the wild. This allowed us to examine genotype-by-environment interactions

118 in genetically distinct populations occurring at about $60^{\circ} \mathrm{N}$ latitude in northern Europe that were

119 expected to show the most pronounced size differences in similar environment (Cassel-

120 Lundhagen et al., 2011). If previously observed latitudinal variation in adult morphology was the

121 result of local evolutionary adaptation rather than phenotypic plasticity, then the size differences

122 between isolated and continuous populations originating from the same latitude should remain in

123 the laboratory-reared individuals. If the size differences between the two populations was 
124 reduced or absent in laboratory-reared individuals, this would indicate a substantial phenotypic

125 plastic component determining the variation between populations.

126

127 Methods

128 The species

129 Roesel's bush cricket is a medium-sized orthopteran species with moderate sexual size

130 dimorphism (the body length is $13-18 \mathrm{~mm}$ for males and 16-20 mm for females; Harz, 1957). In

131 the field it is easily identified by the adult males' characteristic stridulation that is audible almost

132 continuously during the summer and early autumn days if the weather is warm and sunny

133 (Bellmann, 1985). Through its wide distribution range in Europe, and recent western and

134 northern distribution expansion (Kaňuch et al., 2013), it inhabits varied grassland habitats where

135 it feeds on plant matter and small insects (Harz, 1957; Ingrisch \& Köhler, 1998; Maas et al.,

136 2002). Mated females lay their eggs in hollow grass stems or other plant substrates and the

137 nymphs hatch in spring, the first or second year after eggs are laid. The nymphs go through six or

138 seven instars before they are fully developed and in northern Europe individuals usually reach

139 maturity in July. Environmental factors as well as interactions with other individuals influence

140 the species dispersal behaviour between habitats (Berggren, 2004, 2005; Eriksson et al., 2013).

141 The species has two wing forms; a common short-winged form that disperses mainly through

142 walking and an easily identified rare long-winged form that is capable of active flight and

143 usually occurs during rapid colonization events. It has been experimentally shown that

144 macropterism can be environmentally induced (Poniatowski \& Fartmann, 2009), but the

145 frequency of long-winged individuals in our study populations was very low (1.7\%; Kaňuch et

146 al., 2013) and were not sampled in the field nor reared in the laboratory.

148 Sampling

149 We selected four sampling sites that were located at $\sim 60^{\circ} \mathrm{N}$ latitude close to the Baltic Sea coast

150 in northern Europe with the most pronounced differences in individuals' body size but similar

151 climate and environment (Cassel-Lundhagen et al., 2011; Fig. 1A), and that represent two pairs

152 of genetically distinct populations $\left(F_{\mathrm{ST}}=0.04-0.18\right.$; Fig. 1B and C; populations were genotyped

153 by seven polymorphic microsatellite loci in the study by Kaňuch et al., 2013). Two sites

154 represented the continuous range of the species distribution in Finland and Estonia (KAA, TAL) 
155 and two sites represented isolated populations on the Åland Islands and in Sweden (ALA, VAS).

156 These sites contain well established populations and were sampled from the centre of their

157 distribution at each site, in habitat patch size of ca. 2-4 ha, to avoid any possible issues with

158 morphological differences arising from dispersing/colonising individuals at the range margin, or

159 in establishing populations. In order to disentangle the effects of genetic versus environmental

160 drivers of morphological differences in isolated populations of $M$. roeselii, we used individuals

161 collected from three different sampling occasions at each of the four sites. The first sampling was

162 of adult individuals collected in the field between August 9 - September 10, 2008 (from the

163 previous study by Cassel-Lundhagen et al., 2011). The second sampling was of 1st and 2nd

164 instar nymphs between June 3-9, 2010 (approximately 60 nymphs per site) that were then reared

165 under controlled laboratory conditions. The third sampling was adults collected between August

$16626-29,2010$. Thus, we had wild-caught adults from all sites in different years (2008 \& 2010) to

167 examine between-year effects of different natural environmental conditions on morphological

168 traits from isolated versus continuous populations. In addition, we had individuals sampled from

169 all sites in the same year (2010) as nymphs and reared under controlled conditions to compare

170 with wild-caught adults from the same cohort exposed to natural environmental variation. In

171 Orthoptera, initial offspring size is generally correlated with egg size, which is determined by the

172 mother's size with some paternal contribution (Weigensberg et al., 1998). Although temperature,

173 moisture and photoperiod can generate variation in embryonic development of M. roeselii,

174 especially in length of diapause (Ingrisch, 1986a, b, c), there is no evidence that other indirect

175 maternal determinants of embryonic environment can significantly contribute to the variation in

176 offspring body size of this or related species. As eggs of all tested populations have developed in

177 very similar environmental conditions of semi-natural managed mesophile grassland habitats

178 located close to sea level and at the same latitude, where annual mean temperature was about 5

$179{ }^{\circ} \mathrm{C}$ and precipitation about $600 \mathrm{~mm}$ (Fig. 1A), we were confident with using early instars hatched

180 in the field for our laboratory rearing. There was no indication that other environmental factors

181 (e.g. different communities, competition or predation levels) could result in variation of local

182 body size. To further minimise the risk of maternal effects confounding our results we ensured

183 that habitats were sampled randomly, ensuring mixed origin of independent clutches. Using

184 field-caught nymphs was also necessary because (similar to the study of Simmons \& Thomas

185 2004) we had 100\% mortality in nymphs from captive-reared eggs. 

and 1 to 14 females per site and year (Table 1). The nymphs collected in 2010 were after transport to the lab housed in individual cages (dimensions of $8 \times 10 \times 10 \mathrm{~cm}$ ) with ad libitum access to food (fresh grass, pollen, fruit muesli and fortified dietary pellets Rep-Cal ${ }^{\circledR}$ Cricket Food) and water in a climate controlled room with natural and warm light in Uppsala, Sweden. All populations were thus kept in the same conditions with a temperature ranging from 23 to 25 ${ }^{\circ} \mathrm{C}$, and because of natural lighting from north-facing windows the day-night cycle was kept the same as individuals in the field were exposed to. Such parameters contributed to the insects' physiological well-being that ensured easy nymphal development in the rearing facility (Ingrisch, 1978). The nymphs were moved to new clean cages every week to ensure optimal standardised rearing conditions. Despite some natural mortality during preimaginal development we reared 18-28 adult males and 14-24 adult females from each of the four sites to adulthood in the lab (Table 1). After about three days after the final moult and reaching of adulthood, all individuals were stored in 95\% ethanol and kept in room temperature until measured.

Morphological measurements

202

Adult body size measurements were based around four morphological traits for each sex: the length of the femur, forewing, pronotum and genital appendages (male's cerci and female's ovipositor; Fig. 2). In paired organs, we used the right counterpart. These traits were chosen because they represent a range of responses to latitude found in Cassel-Lundhagen et al. (2011); note that while femur, pronotum and gential appendages showed obvious differences in the size cline response between isolated and continuous populations, wings showed little or no size-cline difference (Cassel-Lundhagen et al., 2011). For wild-caught adults in 2008, measurements were done using digital hand-held callipers. However, for the laboratory reared and wild-caught adult individuals sampled in 2010, measurements were undertaken using a different digital technique

211 to reduce observer error in measurement. For this, the body parts of interest were digitally

212 photographed at a standard focal distance and the distance between landmark points (Fig. 2) was

213 measured using the software tpsDIG2 (Rohlf, 2013). To ensure the measurements taken using

214 callipers in 2008 were comparable to those using the digital photography method in 2010

215 (individuals from the Cassel-Lundhagen et al. 2011 study were not available for re- 
217 both techniques for all traits. Using these data, a simple calibration model was then used to

218 convert all calliper measurements to an equivalent digital measure for the 2008 data (Appendix

219 S1 and S2). Although the two ways of measuring traits were strongly correlated (correlation

220 coefficient $r=0.85-0.99$ ) and allowed a high degree of precision when converting from manual

221 to digital measurements, there was some uncertainty in the conversion factor. To account for this

222 uncertainty, we used a Bayesian approach in both the calibration and subsequent analyses. This

223 allowed us to use the uncertainty in the conversion estimate as a measure of observational error

224 in the subsequent models (Appendix S1 and S2); this ensured that any error in conversion factors

225 was accurately reflected in the errors of the estimates from the regression models described

226 below.

227

228 Statistical analyses

229 For each of the four morphological traits we fitted a general linear model that related the size of

230 the trait to the following explanatory variables: (1) isolation to examine the difference between

231 continuous and isolated populations, (2) origin for wild-caught versus laboratory-reared adults,

232 (3) sex for males versus females (for femur, pronotum and wing), and (4) year to control for the

233 between-year effect of different environmental conditions in the field in 2008 and 2010. Because

234 of potential interactions between the first three variables, we also included the following second

235 and third order interaction terms isolation*sex, isolation*origin, origin*sex,

236 isolation*origin*sex. This allowed us to examine the effect of each of these factors and to

237 produce model predictions for each trait based on sex, origin and degree of isolation. To account

238 for any additional differences in morphology between sites, the site effect was included as an

239 adjustment parameter on the intercept (a 'random effect'). To best estimate the range of probable

240 values for each trait and to include the observational uncertainty from the calibration model

241 (above), we used a Bayesian framework with minimally informative priors (see Appendix S1 and

242 S2). The additional advantage of using a Bayesian approach is that all estimated variables and

243 anything derived from these are posterior probability distributions. This allowed us to directly

244 calculate the probability that traits in isolated populations were larger than those from continuous

245 populations (either in general, sex-specific or origin-specific) by simple subtraction of the

246 predictions for each group we were interested in (e.g. male lab-reared adult femur length from

247 isolated population versus male lab-reared adult femur length from continuous population). Here, 
248 the proportion of the resulting posterior distribution that is above zero is the probability that

249 group isolated $>$ group continuous (

250 a probability of 0.50 indicates the mean estimate for the difference $=0$ and has no predictive

251 value; thus, parameters and derived variables where the posterior distribution has lower overlaps

252 with zero can be considered increasingly important to the process being modelled (Low et al.,

253 2016). We used a Bayesian Gibb's sampler (JAGS) called from R (R Core Team, 2016) using

254 the 'rjags' package (Plummer et al., 2016) to estimate final model parameters and generate

255 predictions. For each model, we ran two independent chains and discarded the first 10000 values.

256 Posteriors were estimated from 10000 additional samples from the MCMC chain. Convergence

257 was checked by visual inspection of trace plot stability and mixing. Model fitting was checked

258 for the predicted means and coefficients of variation compared to the original data, using

259 posterior predictive checks based on 'Bayes P' values being between $0.1 \& 0.9$. We report

260 posterior means and $95 \%$ credible intervals for estimated model parameters and predictions

261 unless otherwise stated.

262

263 Results

264 Both males and females from the isolated populations had longer femurs, pronotums and genital 265 appendages (cerci and ovipositor) than those from the continuous populations (Table 2 and Fig.

266 3). For both sexes there was a high degree of certainty that these traits in the isolated populations

267 were longer (probability > 0.99; Fig. 3, Tables $2 \& 3$ ), with this effect being consistent even

268 when individual populations were considered separately (Table 3). Importantly, these patterns

269 were independent of whether individuals were collected from the wild or reared under

270 environmentally controlled conditions (Fig. 3, Tables 2-4). Thus, although crickets raised in the

271 laboratory were generally smaller than their wild counterparts (Tables $2 \& 4$ ), the size

272 differences between isolated versus continuous populations were similar for the laboratory-

273 reared crickets when compared to wild crickets (Fig. 3 and Table 3). For wings, however, there

274 was no evidence that they were longer in isolated populations for males. The evidence for female

275 wings being longer in isolated populations was weak as the $95 \%$ CIs of the estimated difference

276 between these groups overlapped zero (Fig. 3, Tables 2 \& 3).

277

278 


\section{Discussion}

281 Our laboratory findings suggest that phenotypic variation in both males and females of $M$.

282 roeselii originating from genetically distinct populations in northern Europe is the result of local

283 genetic adaptation rather than phenotypic plasticity. Reduced gene flow increases the probability

284 of genotypic differentiation (Endler, 1977; Lenormand, 2002), but adaptive divergence in natural

285 populations is the complex result of the balance between selection, gene flow and plasticity

286 (Hendry et al., 2002; Crispo, 2008; Raeymaekers et al., 2014). By using controlled, though not

287 fully 'common garden' rearing conditions we found no evidence that phenotypic plasticity

288 contributed significantly to the observed size differences between isolated and continuous

289 populations of $M$. roeselii because similar substantial size differences also remained in the

290 laboratory reared individuals. Environmental settings could have a plastic effect on the size of

291 some traits (at least in females); however, individuals that originated from genetically isolated

292 populations (Fig. 1B and C) were always bigger (Fig. 3) when compared to individuals from

293 latitudinally-matched areas characterised by continuous gene flow between populations. Further,

294 the fact that the founder sources of both isolated populations differed also indicates that possible

295 genetic variation due to historic events does not seem to be responsible for observed

296 morphological differences. ALA was most likely founded from the coast of the Gulf of Finland

297 while VAS was founded from the Baltic coast in Poland with later introduction from Estonia

298 (Kaňuch et al., 2013), yet have similar morphological means and variances (Cassel-Lundhagen et

299 al., 2011). Similarly, a clinal variation in the range of isolated populations (Cassel-Lundhagen et

300 al., 2011) is probably not a result of genetic drift or founder effect, as all these populations have

301 been colonised randomly from different sources (Kan̆uch et al., 2013). Thus although we cannot

302 completely rule out genetic drift effects, the possibility that chance variation explains the clinal

303 patterns of phenotypes found in isolated populations is highly unlikely. Variation in gene flow

304 subsequent to establishment is therefore likely to be of major importance for phenotypic

305 differentiation in this insect species. If such phenotypic variation is a result of an adaptive

306 response to selection in isolated populations, this indicates that high levels of gene flow act to

307 homogenize differences in the continuous populations (Slatkin, 1987; Hendry et al., 2002;

308 Raeymaekers et al., 2014). Although it may appear that the KAA and TAL populations from the

309 continuous species range are separated by the Gulf of Finland, a previous study has shown that 
310 there is intensive gene flow between them via their eastern land bridge in Russia (Kan̆uch et al.,

311 2013). To better elucidate the spatial variation in selection between populations of different

312 levels of gene flow, a comparison of $Q_{\mathrm{ST}} / F_{\mathrm{ST}}$ differentiations within and among groups would

313 however be needed.

314 Despite general predictions on the disruptive effect of gene flow in adaptation, relatively

315 little data exist on different effects of gene flow on local adaptation. Only recent development in

316 genomics allow us to better understand how gene flow can promote adaptation via introgression

317 of adaptive alleles through interbreeding of populations and how local adaptation can be

318 maintained despite high level of gene flow due to spatial or temporal balancing selection

319 (reviewed by Tigano \& Friesen, 2016). Built on Felsenstein's work (1977), García-Ramos \&

320 Kirkpatrick (1997) developed mathematical simulations of the interplay between gene flow and

321 adaptation in peripheral populations that have restricted immigration of new individuals (and

322 their alleles) from the main species' range. They demonstrated that a response to local selection

323 pressures could result in a rapid and substantial evolution of traits when a population is isolated.

324 Apparently, the relatively short time since the first introduction of Roesel's bush-crickets to the

325 isolated sites studied (75-130 years; Kan̆uch et al., 2013), is enough time for the observed size

326 variation to evolve. Our results are in agreement with larger body size in isolated populations

327 from colder latitudes found in this species (Cassel-Lundhagen et al., 2011). However, rapid

328 evolution of a positive Bergmann size cline is probably limited for small fast-developing insects.

329 For them the short season in northern latitudes might not heavily reduce time for ontogenesis,

330 contrary to that of large-sized species with long development times (Blanckenhorn \& Demont,

331 2004; Whitman, 2008; Stillwell, 2010; Fabian et al., 2015).

332 Genetic data have previously suggested that multiple introductions of individuals to the

333 isolated populations have occurred since the first establishment of M. roeselii, but that there is

334 little or no ongoing gene flow between these populations and surrounding or founding

335 populations (see $F_{\mathrm{ST}}$ values in Fig. 1B). Although some random genetic processes are still

336 possible in generating the observed differences (Kaňuch et al., 2014), climate-induced selection

337 acting on the morphological traits appears to be strong enough to cause rapid divergence in a

338 cold environment with a high level of seasonality (Huey et al., 2000; Lawson \& Weir, 2014;

339 Krehenwinkel et al., 2016). This does not seem to be the case, however, for wing length. In

340 Cassel-Lundhagen et al. (2011) the size cline variation was similar for both isolated and 
341 continuous populations (i.e. positive but small in both males and females). This suggests that if

342 any cline variation does occur for this trait, it may be driven by a factor that can overcome the

343 homogenizing gene flow effect in the continuous populations. However, given the results here

344 and in Cassel-Lundhagen et al. (2011), it is possible that this trait simply does not respond to

345 latitudinal variation. The rate of trait evolution may also be elevated in novel environments

346 during species' range expansion (Krehenwinkel et al., 2016). The hypothesis posed previously

347 that the species adapt to local optima (Cassel-Lundhagen et al., 2011), is also supported by recent

348 successful colonization events in northern latitudes (Preuss et al., 2014).

349 Our study highlights that environmental factors do not exclusively drive the phenotypic

350 expression of local adaptation (Raeymaekers et al., 2014). However, to learn about the adaptive

351 effect of bigger body size and its expression in isolated populations of $M$. roeselii in northern

352 Europe, an analysis of life history traits that maximize reproductive success is needed. Although

353 very little is known about the environmentally determined effect of body size on reproductive

354 behaviour, bush-cricket males have been found to prefer larger females in colder conditions

355 (Kaňuch et al., 2015). Additionally, a female's size is a primary factor positively correlated to

356 the number of offspring (Honěk, 1993), and body size is maternally inherited for both sexes

357 (Weigensberg et al., 1998). One concern regarding the interpretation of our study is the

358 possibility of confounding maternal effects because reared nymphs were field collected and their

359 parents and embryonic development was not controlled. While these effects must be

360 acknowledged, we were careful to minimise their impact because individuals in the habitat were

361 sampled randomly, ensuring mixed origin of independent clutches. In addition, nymphs collected

362 were early instars whose age differential was $<1$ week, allowing us to be confident that maternal

363 effects and/or different phenology contributed little to variation of nymphal development in the

364 lab. If the species has a high rate of molecular evolution due to relatively quick generation

365 turnover, high fecundity and short lifespan, restricted gene flow will probably not have

366 deleterious effects in isolated populations (Kaňuch et al., 2014). Thus to fully understand the

367 effect of genetic drivers on species' phenotypic variation we need to also estimate the temporal

368 and spatial extent of gene flow associated with founder events (Berggren, 2008), and the

369 possibility of maternal effects on phenotype by examining multiple generations of lab-reared

370 individuals and their crosses. Such an approach could be possible in the case of M. roeselii in

371 northern Europe due to known colonization routes (Kaňuch et al., 2013) and their ability to be 
372 reared in the laboratory that allow us to couple genetic data with morphological variation

373 (Cassel-Lundhagen et al., 2011). In addition, a broader study utilising a 'common garden

374 experiment' across the entire latitudinal range would remove any lingering doubts as to the

375 relative role of genetics in these patterns and their possible interactions with latitudinal variables.

376

377 Conclusions

378 Controlled laboratory conditions revealed no evidence that phenotypic plasticity contributed

379 significantly to the observed differences in three selected body traits (lengths of femur, pronotum

380 and genital appendages) between genetically distinct populations of $M$. roeselii in northern

381 Europe. While climate characteristics of latitudinally-matched pairs of populations (Fig. 1A) are

382 similar, lack of ongoing gene flow into the isolated populations (Fig. 1B and C) is implicated as

383 a cause of these patterns. Thus, our results are consistent with expectations based on a tension

384 between gene flow (as a homogenising force) and divergent climate-related selection (as a

385 diversifying force) that plays out differently in isolated versus continuous populations.

386

387 Acknowledgments

388 We thank Luc F. Bussière for comments on an earlier version of the manuscript and three

389 anonymous reviewers are acknowledged for valuable suggestions which helped to improve our

390 work.

391

392 Additional information and declarations

393

394 Animal ethics

395 All applicable national and international guidelines for the care and use of animals were

396 followed.

397

398 Data availability

399 The raw measurements are available in the Supplemental file.

400

401 Author's contributions 
402 Anna Cassel-Lundhagen, Peter Kaňuch, Åsa Berggren and Ane T. Laugen conceived the study 403 and designed the experiment. Peter Kaňuch and Berrit Kiehl collected field data and Berrit Kiehl 404 reared and measured insects in the lab. Mathew Low performed statistical analyses. Peter 405 Kaňuch, Berrit Kiehl, Anna Cassel-Lundhagen, Ane T. Laugen, Mathew Low and Åsa Berggren 406 wrote the manuscript and all authors revised it critically.

407

408

409

\section{References}

Ahlén I. 1995. En isolerad population av ängsvårtbitare (Metrioptera roeseli) på skånska sydkusten. Entomologisk Tidskrift 116:187-188

Albrecht Z. 1963. Eesti sihktivivalised: Orthoptera s. Saltatoria. Tartu: Eesti Teaduste Akadeemia.

Angilletta JMJ, Dunham AE. 2003. The temperature-size rule in ectotherms: simple evolutionary explanations may not be general. American Naturalist 162:332-342

Atkinson D, Begon M, Fitter AH. 1994. Temperature and organism size - a biological law for ectotherms? In: Begon M, Fitter AH, ed. Advances in ecological research. Vol 25. Oxford: Academic Press, 1-58.

Barnett KL, Facey SL. 2016. Grasslands, invertebrates, and precipitation: A review of the effects of climate change. Frontiers in Plant Science 7:1196

Bavnhøj H. 1996. Nye fund af løvgræshoppen Metrioptera roeseli (Hagenbach) i Danmark. Flora og Fauna 101:61-64.

Bellmann H. 1985. Heuschrecken, beobachten, bestimmen. Melsungen: J Neumann - Neudamm $\mathrm{GmbH}$.

Berggren Å. 2004. Impact of grazing on individual male movement in Roesel's bush-cricket Metrioptera roeseli: one possible clue to species range expansion. Journal of Insect Behavior 17:419-429

Berggren Å. 2005. The effects of conspecifics on individual male movement in Roesel's bushcricket Metrioptera roeseli. Ecological Entomology 30:480-483

Berggren $\AA$. 2008. The effects of population and landscape ecology on body size in orthopterans. Journal of Orthoptera Research 17:183-188 
432 Berner D, Thibert-Plante X. 2015. How mechanisms of habitat preference evolve and promote 433 divergence with gene flow. Journal of Evolutionary Biology 28:1641-1655

434 Blanckenhorn WU, Demont M. 2004. Bergmann and converse Bergmann latitudinal clines in arthropods: two ends of a continuum? Integrative and Comparative Biology 44:413-424

Blanckenhorn WU, Stillwell RC, Young KA, Fox CW, Ashton KG. 2006. When Rensch meets Bergmann: does sexual size dimorphism change systematically with latitude? Evolution 60:2004-2011

Bolnick DI, Nosil P. 2007. Natural selection in populations subject to a migration load. Evolution 61:2229-2243

Cassel-Lundhagen A, Kaňuch P, Low M, Berggren Å. 2011. Limited gene flow may enhance adaptation to local optima in isolated populations of the Roesel's bush cricket (Metrioptera roeselii). Journal of Evolutionary Biology 24:381-390

Chown SL, Gaston KJ. 2009. Body size variation in insects: a macroecological perspective. Biological Reviews 85:139-169

Crispo E. 2008. Modifying effects of phenotypic plasticity on interactions among natural selection, adaptation and gene flow. Journal of Evolutionary Biology 21:1460-1469

Detzel P. 1998. Die Heuschrecken Baden-Württembergs. Eugen: Ulmer.

Endler JA. 1977. Geographic variation, speciation, and clines. Princeton, New Jersey: Princeton University Press.

Eriksson A, Low M, Berggren A. 2013. Influence of linear versus network corridors on the movement and dispersal of the bush-cricket Metrioptera roeseli (Orthoptera: Tettigoniidae) in an experimental landscape. European Journal of Entomology 110:81-86

Felsenstein J. 1977. Multivariate normal genetic model with a finite number of loci. In: Pollak E, Kempthorne O, Bailey Jr TB, eds. Proceedings of the international conference on quantitative genetics. Ames: Iowa State Univ Press, 227-246.

García-Ramos G., Kirkpatrick M. 1997. Genetic models of adaptation and gene flow in peripheral populations. Evolution 51:21-28 
462 Harz K. 1957. Die Orthopteren Europas - The Orthoptera of Europe. Vol. II. The Hague: Dr. W. $463 \quad$ Junk B.V.

464 Hendry AP, Taylor EB, McPhail JD. 2002. Adaptive divergence and the balance between

465 selection and gene flow: lake and stream stickleback in the Misty system. Evolution

$466 \quad 56: 1199-1216$

467 Honěk A. 1993. Intraspecific variation in body size and fecundity in insects: a general

468 relationship. Oikos 66:483-492

469 Huey RB, Gilchrist GW, Carlson ML, Berrigan D, Serra L. 2000. Rapid evolution of a

470 geographic cline in size in an introduced fly. Science 287:308-309

471 Ingrisch S. 1986. The plurennial life-cycles of the European Tettigoniidae (Insecta, Orthoptera).

472 1. The effect of temperature on embryonic-development and hatching. Oecologia

$473 \quad 70: 606-616$

474 Ingrisch S. 1986. The plurennial life-cycles of the European Tettigoniidae (Insecta, Orthoptera).

475 2. The effect of photoperiod on the induction of an initial diapause. Oecologia 70:617$476 \quad 623$

477 Ingrisch S. 1986. The plurennial life-cycles of the European Tettigoniidae (Insecta, Orthoptera).

478 3. The effect of drought and the variable duration of the initial diapause. Oecologia

$479 \quad 70: 624-630$

480 Ingrisch S. 1978. Labor- und Freilanduntersuchungen zur Dauer der postembryonalen

481 Entwicklung einiger mitteleuropäischer Laubheuschrecken (Orthoptera: Tettigoniidae)

482 und ihre Beeinflussung durch Temperatur und Feuchte. Zoologische Anzeiger 200:309_

$483 \quad 320$

484 Ingrisch S, Köhler G. 1998. Die Heuschrecken Mitteleuropas. Die Neue Brehm Bücherei Bd.

485 629. Magdeburg: Westarp Wissenschaften.

486 de Jong J, Kindvall O. 1991. Cikadvårtbitaren Metrioptera roeseli - nykomling eller hotad

487 relikt? Fauna och Flora 86:214-221

488 Jombart T. 2008. adegenet: a R package for the multivariate analysis of genetic markers.

489 Bioinformatics 24:1403-1405

490 Kan̆uch P, Berggren Å, Cassel-Lundhagen A. 2013. Colonization history of Metrioptera roeselii

491

492 in northern Europe indicates human-mediated dispersal. Journal of Biogeography 40:977-987 
493 Kaňuch P, Berggren Å, Cassel-Lundhagen A. 2014. Genetic diversity of a successful colonizer: 494 isolated populations of Metrioptera roeselii regain variation at an unusually rapid rate. $495 \quad$ Ecology and Evolution 4:1117-1126

496 Kaňuch P, Jarčuška B, Kovács L, Krištín A. 2015. Environmentally driven variability in sizeselective females' mating frequency of bush-cricket Pholidoptera griseoaptera. Evolutionary Ecology 29:787-797

Karjalainen S. 2009. Suomen heinäsirkat ja hepokatit. Helsinki: Tammi Publishers.

501

502

503

504

505

506

507

508

509

510

511

512

513

514

515

516

517

518

519

520

521

Kawecki T, Ebert D. 2004. Conceptual issues in local adaptation. Ecology Letters 7:1225-1241

Kenyeres Z, Cservenka J. 2014. Effects of climate change and various grassland management practices on grasshopper (Orthoptera) assemblages. Advances in Ecology 2014:601813

Krehenwinkel H, Rödder D, Năpăruş-Aljančič M, Kuntner M. 2016. Rapid genetic and ecological differentiation during the northern range expansion of the venomous yellow sac spider Cheiracanthium punctorium in Europe. Evolutionary Applications 9:12291240

Lawson AM, Weir JT. 2014. Latitudinal gradients in climatic-niche evolution accelerate trait evolution at high latitudes. Ecology Letters 17:1427-1436

Lenormand T. 2002. Gene flow and the limits to natural selection. Trends in Ecology and Evolution 17:183-189

Low M, Tsegaye AT, Ignell R, Hill S, Elleby R, Feltelius V, Hopkins R. 2016. The importance of accounting for larval detectability in mosquito habitat-association studies. Malaria Journal 15:1-9

Maas S, Detzel P, Staudt A. 2002. Gefährdungsanalyse der Heuschrecken Deutschlands Verbreitungsatlas, Gefährdungseinstufung und Schutzkonzepte. Bonn-Bad Godesberg: Bundesamt für Naturschutz.

Pedersen SH, Ferchaud A-L, Bertelsen MS, Bekkevold D, Hansen MM. 2017. Low genetic and phenotypic divergence in a contact zone between freshwater and marine sticklebacks: gene flow constrains adaptation. BMC Evolutionary Biology 17:130

Plummer M, Stukalov A, Denwood M. 2016. rjags: Bayesian Graphical Models using MCMC. Available at https://cran.r-project.org/package=rjags (accessed 2 November 2017) 
522 Poniatowski D, Fartmann T. 2009. Experimental evidence for density-determined wing

523

524

525

526

527

528

529

530

531

532

533

534

535

536

537

538

539

540

541

542

543

544

545

546

547

548

549

550

551

552 dimorphism in two bush-crickets (Ensifera: Tettigoniidae). European Journal of Entomology 106:599-605

Preuss S, Low M, Cassel-Lundhagen A, Berggren Å. 2014. Evaluating range-expansion models for calculating non-native species expansions. Ecology and Evolution 4:2812-2822

R Core Team. R. 2016. A language and environment for statistical computing. Vienna: R Foundation for Statistical Computing. http://www.R-project.org/.

Raeymaekers JAM, Konijnendijk N, Larmuseau MHD, Hellemans B, De Meester L, Volckaert FAM. 2014. A gene with major phenotypic effects as a target for selection vs. homogenizing gene flow. Molecular Ecology 23:162-181

Rohlf FJ. 2006. tpsDIG2. Available at https://tpsdig2.software.informer.com/download/ (accessed at 10 March 2013)

Simmons AD, Thomas CD. 2004. Changes in dispersal during species' range expansions. The American Naturalist 164:378-395

Slatkin M. 1987. Gene flow and the geographic structure of natural populations. Science 236:787-792.

Stillwell RC. 2010. Are latitudinal clines in body size adaptive? Oikos 119:1387-1390

Terribile LC, Olalla-Tarraga MA, Diniz JAF, Rodriguez MA. 2009. Ecological and evolutionary components of body size: geographic variation of venomous snakes at the global scale. Biological Journal of Linnean Society 98:94-109

Tigano A, Friesen VL. 2016. Genomics of local adaptation with gene flow. Molecular Ecology $25: 2144-2164$

van Voorhies W. 1996. Bergmann size clines: a simple explanation for their occurrence in ectotherms. Evolution 50:1259-1264

Weigensberg I, Carriere Y, Roff DA. 1998. Effects of male genetic contribution and paternal investment to egg and hatchling size in the cricket, Gryllus firmus. Journal of Evolutionary Biology 11:135-146

Whitman DW. 2008. The significance of body size in the Orthoptera: a review. Journal of Orthoptera Research 17:17-34

Peer) reviewing PDF | (2020:06:49791:1:2:NEW 5 Aug 2020) 
Figures legends

574

Figure 1: Study sites (circles) within the range of Metrioptera roeselii in northern Europe where nymphs and adults were sampled. (A) The populations KAA and TAL are situated in

577 the species continuous distribution range and connected via Russia in the east; VAS and ALA

578 are isolated population sites. Hatched area shows range in 2010. For details about colonization

579 history see Kaňuch et al. (2013). Climate data were downloaded from WorldClim.org database in

$580 \sim 1 \mathrm{~km}$ resolution. (B) Pairwise genetic differences between populations by $F_{\mathrm{ST}}$ values corrected

581 for null alleles by the ENA method. All values are significant according to a G-test $(P<0.05$

582 after Bonferroni correction). (C) Genetic distances between individuals sampled in 2008 
583 examined by a Principal Coordinates Analysis (PCoA) of the R-package 'adegenet' 2.1.1

584 (Jombart, 2008). Ellipses indicate credible distribution of the individuals in to different clusters. 585

586 Figure 2: The locations of landmarks (white circles) for size measurements of

587 morphological traits of adult Metrioptera roeselii individuals. (A) Hind femur, (B) forewing,

588 (C) pronotum, (D) male's cerci and (E) female's ovipositor. The black line at each trait

589 represents a scale bar of $1 \mathrm{~mm}$.

590

591 Figure 3: The estimated medians and $95 \%$ credible intervals for the lengths of

592 morphological traits of Metrioptera roeselii. (A) Males grown in the field or (B) reared in the

593 laboratory and (C) females grown in the field or (D) reared in the laboratory. Squares - hind

594 femur, circles - forewing, triangle - pronotum, diamond - cerci/ovipositor. Individuals

595 originated from the sites of the continuous species range (con) and isolated sites (iso) located

596 about $60^{\circ} \mathrm{N}$ latitude in northern Europe. Values on the y-axis are standardised relative to the

597 estimates from the continuous populations, which are set to zero for each trait. For specific

598 estimates of each trait, the differences between traits conditional on sex, rearing condition and

599 genetic isolation, and the probability that they differ from each other see Tables $2-4$.

600 


\section{Table 1 (on next page)}

Numbers of sampled Metrioptera roeselii adults.

Numbers of sampled Metrioptera roeselii adults (males / females) from sites representing continuous range of the species' distribution and sites from reproductively isolated populations in northern Europe. 
1 Table 1: Numbers of sampled Metrioptera roeselii adults (males / females) from sites

2 representing continuous range of the species' distribution and sites from reproductively

3 isolated populations in northern Europe.

\begin{tabular}{llllccc}
\hline Site (code) & $\begin{array}{l}\text { Isolation } \\
\text { level }\end{array}$ & $\begin{array}{l}\text { Latitude } \\
\left({ }^{\circ} \mathrm{N}\right)\end{array}$ & $\begin{array}{l}\text { Longitude } \\
\left({ }^{\circ} \mathrm{E}\right)\end{array}$ & $\begin{array}{l}\text { Field grown } \\
(2008)\end{array}$ & $\begin{array}{l}\text { Laboratory } \\
\text { reared }\end{array}$ \\
\hline Kaarina (KAA) & continuous & 60.43 & 22.39 & $13 / 11$ & $10 / 2$ & $19 / 14$ \\
Talin (TAL) & continuous & 59.52 & 24.82 & $23 / 1$ & $12 / 2$ & $26 / 21$ \\
Åland (ALA) & isolated & 60.26 & 19.93 & $12 / 12$ & $10 / 14$ & $18 / 24$ \\
Västerås (VAS) & isolated & 59.59 & 16.48 & $12 / 12$ & $6 / 8$ & $28 / 23$ \\
\hline
\end{tabular}

4

5 


\section{Table 2 (on next page)}

Model estimates of morphological trait length for Metrioptera roeselii adults

Model estimates of morphological trait length (means \pm SD of the posterior distribution in $\mathrm{mm}$ ) for Metrioptera roeselii adults categorized by sex, origin and genetic isolation. For each trait the probability that values are larger in isolated populations than in the continuous distribution range is given $\left(P_{\text {iso>con }}\right)$. 


\section{Table 2: Model estimates of morphological trait length (means \pm SD of the posterior}

2 distribution in mm) for Metrioptera roeselii adults categorized by sex, origin and genetic

3 isolation. For each trait the probability that values are larger in isolated populations than in the

4 continuous distribution range is given $\left(P_{\text {iso }>\text { con }}\right)$.

\begin{tabular}{lllllll}
\hline \multirow{2}{*}{ Trait (sex) } & \multicolumn{2}{l}{ Field grown individuals } & \multicolumn{3}{c}{ Laboratory reared individuals } \\
& continuous & isolated & $P_{\text {iso }>\text { con }}$ & continuous & isolated & $P_{\text {iso }>\text { con }}$ \\
\hline Males & & & & & \\
Femur & $13.02 \pm 0.09$ & $13.52 \pm 0.08$ & 1.000 & $12.51 \pm 0.10$ & $13.02 \pm 0.09$ & 0.999 \\
Wings & $8.86 \pm 0.12$ & $8.76 \pm 0.11$ & 0.261 & $9.01 \pm 0.13$ & $8.97 \pm 0.12$ & 0.404 \\
Pronotum & $4.06 \pm 0.03$ & $4.38 \pm 0.03$ & 1.000 & $3.88 \pm 0.05$ & $4.16 \pm 0.04$ & 1.000 \\
Cerci & $2.71 \pm 0.03$ & $2.97 \pm 0.03$ & 1.000 & $2.69 \pm 0.04$ & $2.96 \pm 0.03$ & 0.999 \\
Females & & & & & & \\
Femur & $13.97 \pm 0.16$ & $15.04 \pm 0.09$ & 1.000 & $13.56 \pm 0.11$ & $14.25 \pm 0.09$ & 1.000 \\
Wing & $6.20 \pm 0.22$ & $6.41 \pm 0.12$ & 0.795 & $6.20 \pm 0.14$ & $6.37 \pm 0.14$ & 0.856 \\
Pronotum & $4.40 \pm 0.06$ & $4.80 \pm 0.04$ & 1.000 & $3.98 \pm 0.05$ & $4.44 \pm 0.04$ & 1.000 \\
Ovipositor & $5.95 \pm 0.06$ & $6.40 \pm 0.05$ & 1.000 & $5.42 \pm 0.06$ & $6.09 \pm 0.06$ & 0.999 \\
\hline
\end{tabular}

5 


\section{Table 3 (on next page)}

Size difference (in $\mathrm{mm}$ ) between traits measured in isolated versus continuous populations (where the difference is isolated - continuous), conditional on sex and rearing condition.

Size difference (in $\mathrm{mm}$ ) between traits measured in isolated versus continuous populations (where the difference is isolated - continuous), conditional on sex and rearing condition.

Rearing conditions are given for wild field-caught insects (field), those reared under environmentally controlled conditions (laboratory) and a general category where all observations are grouped regardless of rearing condition (general). Estimates are the means $\pm S D$ of the posterior distribution of the differences between populations, generated directly from the regression models (for details see Appendix S1). 
1 Table 3: Size difference (in $\mathbf{m m}$ ) between traits measured in isolated versus continuous 2 populations (where the difference is isolated - continuous), conditional on sex and rearing

3 condition. Rearing conditions are given for wild field-caught insects (field), those reared under

4 environmentally controlled conditions (laboratory) and a general category where all observations

5 are grouped regardless of rearing condition (general). Estimates are the means \pm SD of the

6 posterior distribution of the differences between populations, generated directly from the

7 regression models (for details see Appendix S1).

\begin{tabular}{lccc}
\hline Trait $(\mathrm{sex})$ & field & Rearing conditions & \\
& & laboratory & general \\
\hline Males & $0.51 \pm 0.12$ & $0.51 \pm 0.12$ & \\
Femur & $-0.10 \pm 0.16$ & $-0.03 \pm 0.15$ & $0.51 \pm 0.09$ \\
Wings & $0.32 \pm 0.04$ & $0.28 \pm 0.06$ & $-0.07 \pm 0.11$ \\
Pronotum & $0.26 \pm 0.03$ & $0.27 \pm 0.04$ & $0.29 \pm 0.04$ \\
Cerci & & & $0.27 \pm 0.04$ \\
Females & $1.06 \pm 0.18$ & $0.69 \pm 0.12$ & \\
Femur & $0.15 \pm 0.23$ & $0.17 \pm 0.19$ & $0.87 \pm 0.11$ \\
Wing & $0.39 \pm 0.07$ & $0.46 \pm 0.03$ & $0.16 \pm 0.15$ \\
Pronotum & $0.45 \pm 0.05$ & $0.67 \pm 0.06$ & $0.42 \pm 0.05$ \\
Ovipositor & & $0.56 \pm 0.05$ \\
\hline
\end{tabular}




\section{Table 4 (on next page)}

Site-specific trait estimates in $\mathrm{mm}$ (mean $\pm \mathrm{SD}$ of the posterior distribution from the model) conditional on site type where they were caught and where the insects were reared.

Site-specific trait estimates in $\mathrm{mm}$ (mean $\pm \mathrm{SD}$ of the posterior distribution from the model) conditional on site type where they were caught and where the insects were reared. Consistent with the main results is that: (1) the longer trait length for isolated versus continuous populations in the wild is maintained when the insects are raised under controlled conditions, and (2) these results are consistent and show a high degree of certainty for the femur, pronotum and genital appendage (ovipositor/cerci) traits, and less consistent with a higher degree of uncertainty for the wing trait. 


\section{Table 4: Site-specific trait estimates in $\mathbf{m m}$ (mean \pm SD of the posterior distribution from}

2 the model) conditional on site type where they were caught and where the insects were

3 reared. Consistent with the main results is that: (1) the longer trait length for isolated versus

4 continuous populations in the wild is maintained when the insects are raised under controlled

5 conditions, and (2) these results are consistent and show a high degree of certainty for the femur,

6 pronotum and genital appendage (ovipositor/cerci) traits, and less consistent with a higher degree

7 of uncertainty for the wing trait.

\begin{tabular}{|c|c|c|c|c|c|c|}
\hline Site & Type & Reared & Femur & Pronotum & Ovip./Cerci & Wing \\
\hline \multicolumn{7}{|l|}{ Males } \\
\hline \multirow[t]{2}{*}{ KAA } & continuous & field & $13.02 \pm 0.14$ & $4.02 \pm 0.06$ & $2.74 \pm 0.04$ & $8.81 \pm 0.19$ \\
\hline & & laboratory & $12.21 \pm 0.16$ & $3.82 \pm 0.07$ & $2.67 \pm 0.05$ & $8.79 \pm 0.20$ \\
\hline \multirow[t]{2}{*}{ TAL } & continuous & field & $13.01 \pm 0.13$ & $4.09 \pm 0.04$ & $2.70 \pm 0.04$ & $8.93 \pm 0.16$ \\
\hline & & laboratory & $12.71 \pm 0.14$ & $3.96 \pm 0.07$ & $2.71 \pm 0.05$ & $9.18 \pm 0.16$ \\
\hline \multirow[t]{2}{*}{ ALA } & isolated & field & $13.79 \pm 0.14$ & $4.52 \pm 0.05$ & $2.95 \pm 0.04$ & $8.90 \pm 0.19$ \\
\hline & & laboratory & $13.02 \pm 0.15$ & $4.24 \pm 0.07$ & $2.89 \pm 0.05$ & $9.15 \pm 0.20$ \\
\hline \multirow[t]{2}{*}{ VAS } & isolated & field & $13.39 \pm 0.11$ & $4.30 \pm 0.04$ & $2.98 \pm 0.04$ & $8.68 \pm 0.14$ \\
\hline & & laboratory & $13.01 \pm 0.13$ & $4.10 \pm 0.05$ & $3.03 \pm 0.05$ & $8.86 \pm 0.15$ \\
\hline
\end{tabular}

Females

\begin{tabular}{|c|c|c|c|c|c|c|}
\hline \multirow{2}{*}{ KAA } & continuous & field & $13.95 \pm 0.19$ & $4.40 \pm 0.07$ & $5.70 \pm 0.09$ & $6.19 \pm 0.27$ \\
\hline & & laboratory & $13.31 \pm 0.16$ & $3.86 \pm 0.07$ & $5.43 \pm 0.11$ & $6.02 \pm 0.22$ \\
\hline \multirow[t]{2}{*}{ TAL } & continuous & field & $14.07 \pm 0.32$ & $4.40 \pm 0.14$ & $6.21 \pm 0.09$ & $6.16 \pm 0.38$ \\
\hline & & laboratory & $13.73 \pm 0.14$ & $4.04 \pm 0.06$ & $5.55 \pm 0.09$ & $6.39 \pm 0.19$ \\
\hline \multirow[t]{2}{*}{ ALA } & isolated & field & $15.15 \pm 0.12$ & $4.88 \pm 0.05$ & $6.29 \pm 0.05$ & $6.81 \pm 0.16$ \\
\hline & & laboratory & $14.23 \pm 0.14$ & $4.43 \pm 0.06$ & $6.08 \pm 0.09$ & $6.42 \pm 0.20$ \\
\hline \multirow[t]{2}{*}{ VAS } & isolated & field & $14.89 \pm 0.14$ & $4.72 \pm 0.05$ & $6.49 \pm 0.06$ & $5.88 \pm 0.17$ \\
\hline & & laboratory & $14.26 \pm 0.14$ & $4.43 \pm 0.06$ & $6.27 \pm 0.08$ & $6.37 \pm 0.19$ \\
\hline
\end{tabular}




\section{Figure 1}

Study sites (circles) within the range of Metrioptera roeselii in northern Europe where nymphs and adults were sampled.

Study sites (circles) within the range of Metrioptera roeselii in northern Europe where nymphs and adults were sampled. (A) The populations KAA and TAL are situated in the species continuous distribution range and connected via Russia in the east; VAS and ALA are isolated population sites. Hatched area shows range in 2010. For details about colonization history see Kaňuch et al. (2013). Climate data were downloaded from WorldClim.org database in $\sim 1 \mathrm{~km}$ resolution. (B) Pairwise genetic differences between populations by $F_{\mathrm{ST}}$ values corrected for null alleles by the ENA method. All values are significant according to a G-test ( $P<0.05$ after Bonferroni correction). (C) Genetic distances between individuals sampled in 2008 examined by a Principal Coordinates Analysis (PCoA) of the R-package 'adegenet' 2.1.1 (Jombart, 2008). Ellipses indicate credible distribution of the individuals in to different clusters. 


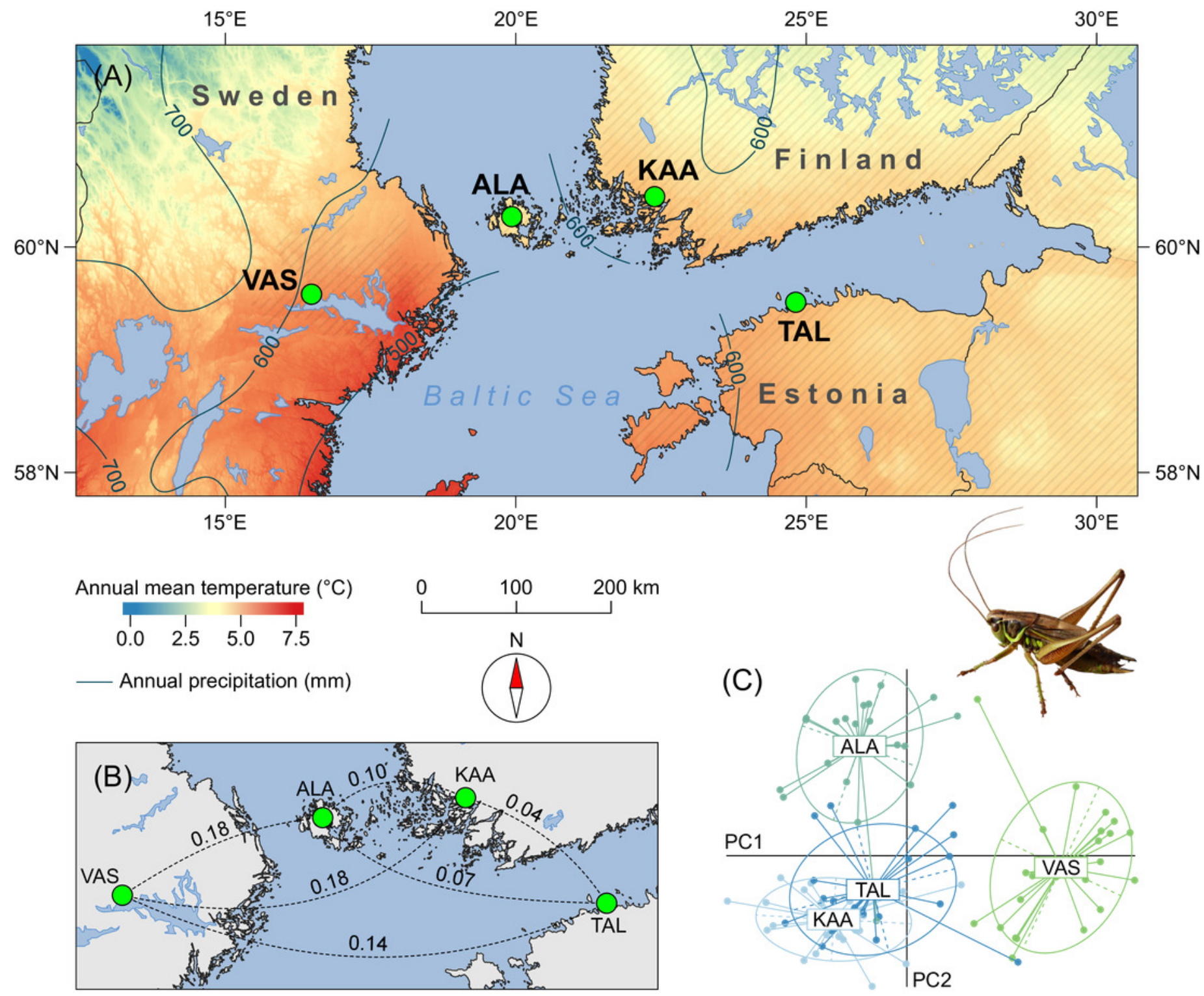




\section{Figure 2}

The locations of landmarks (white circles) for size measurements of morphological traits of adult Metrioptera roeselii individuals.

The locations of landmarks (white circles) for size measurements of morphological traits of adult Metrioptera roeselii individuals. (A) Hind femur, (B) forewing, (C) pronotum, (D) male's cerci and (E) female's ovipositor. The black line at each trait represents a scale bar of $1 \mathrm{~mm}$. 

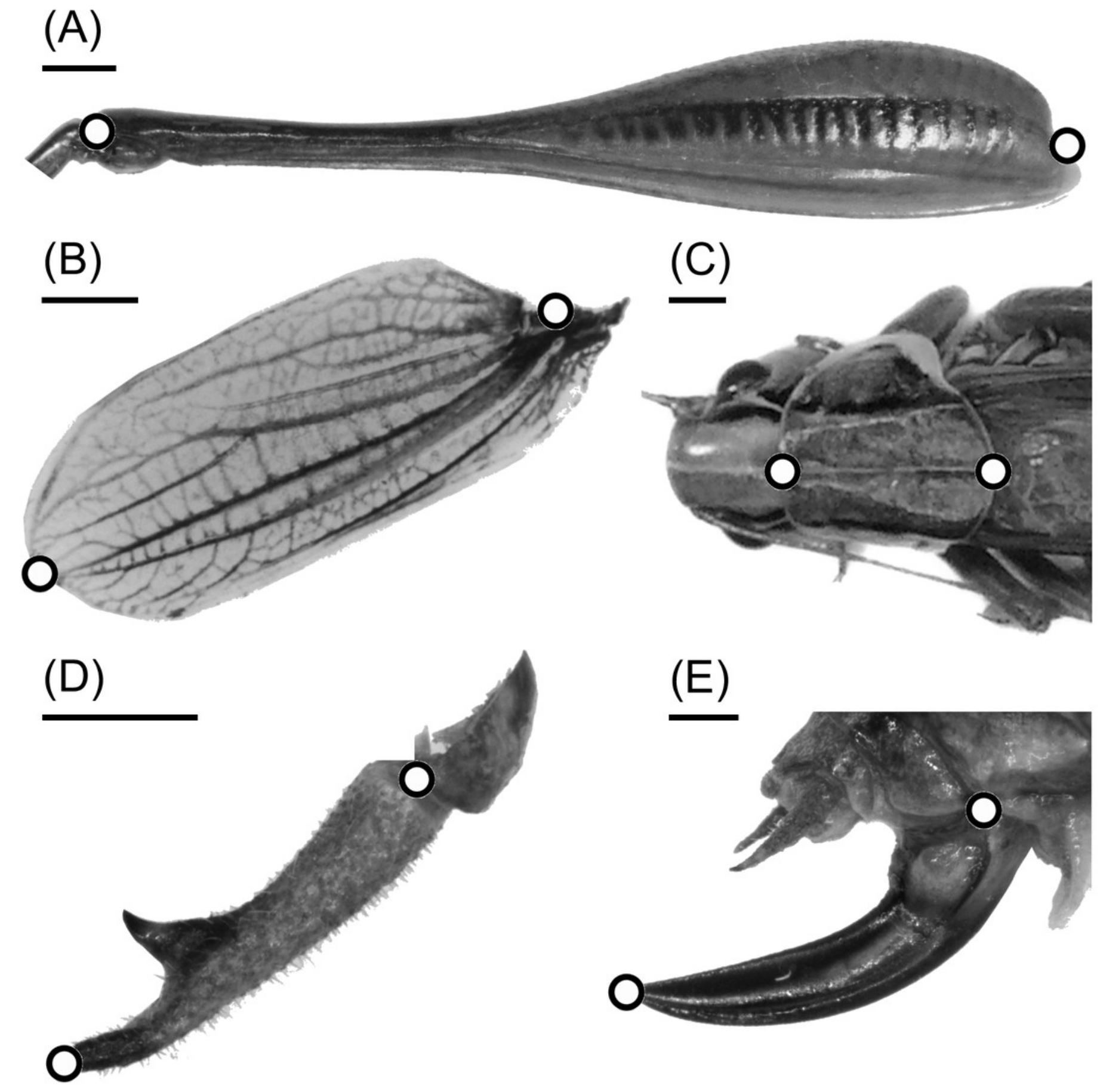


\section{Figure 3}

The estimated medians and $95 \%$ credible intervals for the lengths of morphological traits of Metrioptera roeselii.

The estimated medians and $95 \%$ credible intervals for the lengths of morphological traits of Metrioptera roeselii. (A) Males grown in the field or (B) reared in the laboratory and (C) females grown in the field or (D) reared in the laboratory. Squares - hind femur, circles forewing, triangle - pronotum, diamond - cerci/ovipositor. Individuals originated from the sites of the continuous species range (con) and isolated sites (iso) located about $60^{\circ} \mathrm{N}$ latitude in northern Europe. Values on the $y$-axis are standardised relative to the estimates from the continuous populations, which are set to zero for each trait. For specific estimates of each trait, the differences between traits conditional on sex, rearing condition and genetic isolation, and the probability that they differ from each other see Tables 2-4.

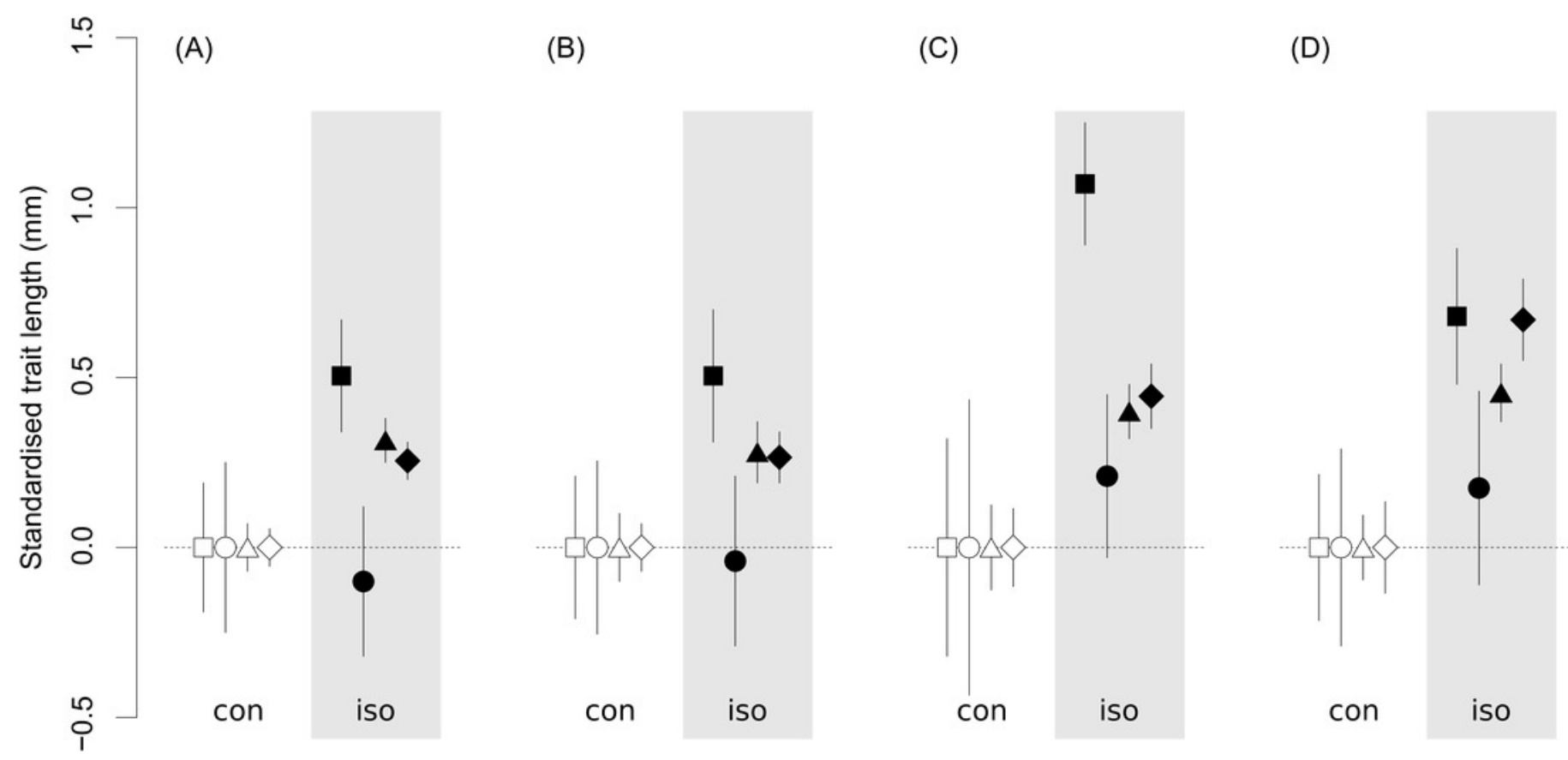

